\title{
Museos, desarrollo y cambio: la reacción de los "espacios banales"
}

Cícero Antonio F. de Almeida*

Los museos son territorios simbólicos privilegiados de la contemporaneidad. A lo mejor puede ser una afirmación precipitada o apenas otra utopía museológica. Pero lo que es cierto es que los museos cambiaron o están en movimiento y no se parecen más con aquellos que Fillippo Marinetti quería destruir (Manifesto Futurista, 1909) o con aquellos que Paul Valéry decía en "no morirse de amores" (O problema dos museus, 1923), para apenas nombrar dos de los mas conocidos detractores. Entre los cambios más importantes verificados en los últimos años está el aparecimiento de las iniciativas espontáneas de la creación de nuevos museos, nacidos a partir de la articulación de los movimientos populares organizados, que no eran más únicamente conducidos por los poderes públicos. Una explicación para tal fenómeno es que los museos pasaron a ser vistos y reivindicados como un derecho esencial - hasta el día de hoy, en su gran mayoría, negado - como un espacio contemporáneo de participación y de reacción. Sin embargo, ¿hasta qué punto podemos relacionar los museos, el desarrollo y los cambios sociales?

Para reflexionar sobre esta relación, debemos empezar por preguntarnos sobre el carácter axiométrico. A final, ¿cuál es el concepto de desarrollo que estamos utilizando? ¿Cómo los museos se articulan con los cambios sociales en curso? No tenemos duda de que el tema es absolutamente contemporáneo e instigador, y sirve para proporcionar indicadores para el trabajo por ser desempeñado por los museos en el siglo XXI.

En primer lugar, es necesario aclarar el "lado" seleccionado para la discusión y la "profundidad" de la idea de desarrollo. La terminología ha sido utilizada

\footnotetext{
* Museólogo, profesor de la Escuela de Museología de la Universidad Federal del Estado de Río de Janeiro y coordinador de Patrimonio Museológico del Instituto Brasilero de Museos.
} 
corrientemente como una especie de etapa económica por la sociedad, que puede ser verificada a través de un conjunto de indicadores financieros. Consecuentemente, el término desarrollo — tratándose específicamente de desarrollo social - dejó de ser utilizado como incremento o democratización de los recursos colocados para la disposición colectiva (salud, educación, cultura, etc.), la mejora de la distribución de riquezas o progreso científico, entre tantas otras posibilidades que los diccionarios cuidadosamente insisten en preservar.

En relación con los movimientos de cambios de los museos, encontramos su génesis en los años 1970. Se veían como espacios de preservación de añoranzas, representantes de un determinado segmento social y de su historia. Era imperativo interrumpir una especie de incomunicación del museo con la sociedad y asociarlo a una nueva percepción del papel social desempeñado por la preservación y por la acción cultural. Un fértil período de la crisis marcó la actuación de los museos en las siguientes décadas. Entre las nuevas experiencias que se destacaron fueron aquellas que incorporaron la noción de musealización de territorios, una profunda ruptura con el modelo que privilegiaba el binomio edificio/colecciones. Hubo un desplazamiento del "objeto", como preocupación central de los museos, hacia el "sujeto", y al que pertenece ese objeto en la sociedad.

Entender la historia de los museos y de sus permanencias/rupturas también es entender la propia historia de las ideas. Debemos considerar que, durante la década de 1960 y 1980, otras luchas sociales estaban ocurriendo; y el museo no podía quedarse atrás de esas discusiones. Durante el período, vimos las luchas por la independencia de las últimas colonias europeas en África, la resistencia contra las dictaduras militares en Suramérica, el comprometimiento intelectual y los movimientos estudiantiles, las luchas por el cambio del papel desempeñado por la mujer en la sociedad y la igualdad racial, entre otras. En el camino de tantas luchas, las prácticas culturales fueron pensadas como herramientas poderosas, porque operaban con la afirmación de identidades y, consecuentemente, proporcionaban un diálogo entre diferentes y diferencias.

El papel ejercido, a partir del pensamiento del educador brasileño Paulo Freire, en las nuevas experiencias de los museos durante esa época fue sorprendente, bajo el concepto de concientización, a partir de la transformación del hombre-objeto para hombre-sujeto, de acuerdo con la afirmación de Hugues de Varine en 1979, cuando ejercía el cargo de director del Consejo Internacional de Museos. Varine formuló una de las metáforas mas importantes en 
el cambio de paradigmas de los museos al final de la década de 1970: "El museo como finalidad, el museo como objetivo, es la universidad popular, la universidad para el pueblo a través de los objetos. Lo que es en una universidad normal es el lenguaje de las palabras y, en último caso, el lenguaje de las señales escritas. En el caso del museo, se convierte en el lenguaje de los objetos, de lo concreto". 1

Al final de los años 80, al mismo tiempo en que fueron vencidas las primeras barreras que marcaron una nueva dirección del trabajo de los museos, el avance del pensamiento pragmático propagado por el orden ideológico neoliberal impuso, con la benevolencia de los medios de comunicación, el consenso de desarrollo centralizado exclusivamente en su dimensión económica. El nuevo orden mundial fundado por los gobiernos anglosajones consagró como inexorable la hegemonía económica, la expansión de los mercados y el fin de las fronteras territoriales, fragilizando, consecuentemente, las economías y las expresiones culturales desplazadas del eje territorial hegemónico. El concepto de desarrollo ganó interpretación con base en la lógica de la globalización económica y de la homogenización progresiva de la riqueza, lo que acabaría conduciendo a la humanidad "en dirección de un gobierno global, una paz perpetua y una democracia cosmopolita"; según la evaluación del profesor de economía José Luís Fiori, traería graves consecuencias para las políticas públicas en el campo de la cultura. La cartilla del desarrollo liberal creó el concepto de "economía de la cultura", utilizado en diversos programas de gobierno de la época.

En el campo de los museos, un choque de tendencias marcó la década de 1990, principalmente en Brasil, al ser ejemplificado por la oposición entre el más tímido surgimiento de iniciativas populares de la creación de nuevos museos o de la "apropiación" de los que ya existían y el modelo Guggenheim, conocido como la primera franquicia museológica. En el año 2000, surgió un caso particular, por iniciativa de la alcaldía de la ciudad de Río de Janeiro, al implantar el Museo Guggenheim en la región portuaria de la ciudad, por el orden de dos millones de dólares americanos (que vendrían de los cofres públicos), aplicados en una institución privada con sede en EE.UU. Debemos recordar que el movimiento fue abortado después de una amplia movilización popular, que denunciaba lo paradójico de la situación, ya que era evidente el abandono de las estructuras museológicas municipales existentes, además del poco incentivo por parte de la propia alcaldía para nuevos proyectos de

1 Varine-Bohan, Hugues de. Os museus no mundo. Rio de Janeiro: Salvat Editora do Brasil, 1979, p.19. 
los museos revindicados por la sociedad. Para tener una idea de la dimensión ideológica de la "economía de la cultura", podemos recordar la opinión de Thomas Krens, presidente de la Fundación Guggenheim, formulada en 1999, de que los museos sintonizados con los "nuevos tiempos" ofrecerían "oportunidades para comer y oportunidades para hacer compras".

La hegemonía del nuevo capitalismo y la perversión de los efectos del proceso de globalización fomentaron, entre tanto, reacciones inmediatas, como la conocida "reacción de los espacios banales", expresión utilizada por el geógrafo Milton Santos. ${ }^{2}$ Para Santos, los "espacios banales" abrigan la mayor parte de la población, reaccionan a los "espacios integrados", excluyentes, que dominan los flujos globalizados del dinero y de la información. Se desarrollan en esos espacios las culturas populares, las bases de una nueva "utopía globalitaria". Para el geógrafo, "el cambio histórico en perspectiva provendrá de un movimiento de abajo para arriba, siendo los países subdesarrollados los actores principales y no los países ricos; los sin herencias y los pobres, y no los opulentos y otras clases obesas; el individuo participa de las nuevas masas y no del hombre encadenado; el pensamiento libre y no el discurso único".

Podemos compararlo con la "utopía globalitaria" identificada por Milton Santos, y reconocer que los museos también se están transformando en herramientas hasta para el servicio de los "espacios banales". Segmentos sociales contemporáneos que todavía permanecen al margen, prácticamente "invisibles", están reinventando el nuevo museo del siglo XXI. Son museos construidos como reacción, en el sentido indicado por Milton Santos. Surgen en las favelas de Río de Janeiro, en los barrios periféricos de las grandes metrópolis, en aldeas indígenas. A esas luchas, también están condicionadas la lucha por la tierra, el derecho de las minorías, por el reconocimiento de las culturas "marginales". La idea stricto sensu de la "economía de la cultura", entendida únicamente como articuladora de la distribución y del consumo de bienes y servicios, empezó a perder espacio para una nueva escala productiva, alterando la exclusividad y el monopolio de los "gestores", personajes creados en los mecanismos legales válidos para los procesos de incentivo cultural. Entonces, la nueva "economía de la cultura" debe estar cerca del concepto de utopía globalitaria.

Aquí está la llave para el nuevo axioma. El desarrollo en el área de los museos

2 Santos, Milton. Por uma outra globalizacao: do pensamento único à consciencia universal. Rio de Janeiro: Record, 2008. 
no puede ser concebido como una sencilla "dictadura de taquilla" o como algo más de los productores/gestores/captadores. El desafío señalado por la emergencia de los "espacios banales" refuerza la importancia de la implantación de prácticas museológicas ajustadas al principio de democratización de la cultura y defensa de la diversidad. Debemos pensar en las pequeñas iniciativas de los museos, en su fuerza local, facilitar la emergencia de los nuevos agentes sociales y estimular la construcción de las redes, porque cada museo cumpliría un papel específico de acuerdo con su ambiente cultural. El carácter desarrollador del museo está en su capacidad de articular el pensamiento libre (en vez de corroborar el mismo pensamiento "único" transnacional), promover nuevos

protagonistas históricos, estimular percepciones variadas del espacio y del tiempo, engendrar pasado y presente (en contra de la añoranza contemplativa) $\mathrm{y}$, finalmente, permitir el pensamiento y soñar con el futuro.

\section{Referentes bibliográficos}

Santos, Milton. Por uma outra globalizacao: do pensamento único à consciencia universal. Rio de Janeiro: Record, 2008.

Varine-Bohan, Hugues de. Os museus no mundo. Rio de Janeiro: Salvat Editora do Brasil, 1979.

Santos, Milton. Por uma outra globalizacao: do pensamento único à consciencia universal. Rio de Janeiro: Record, 2008. 


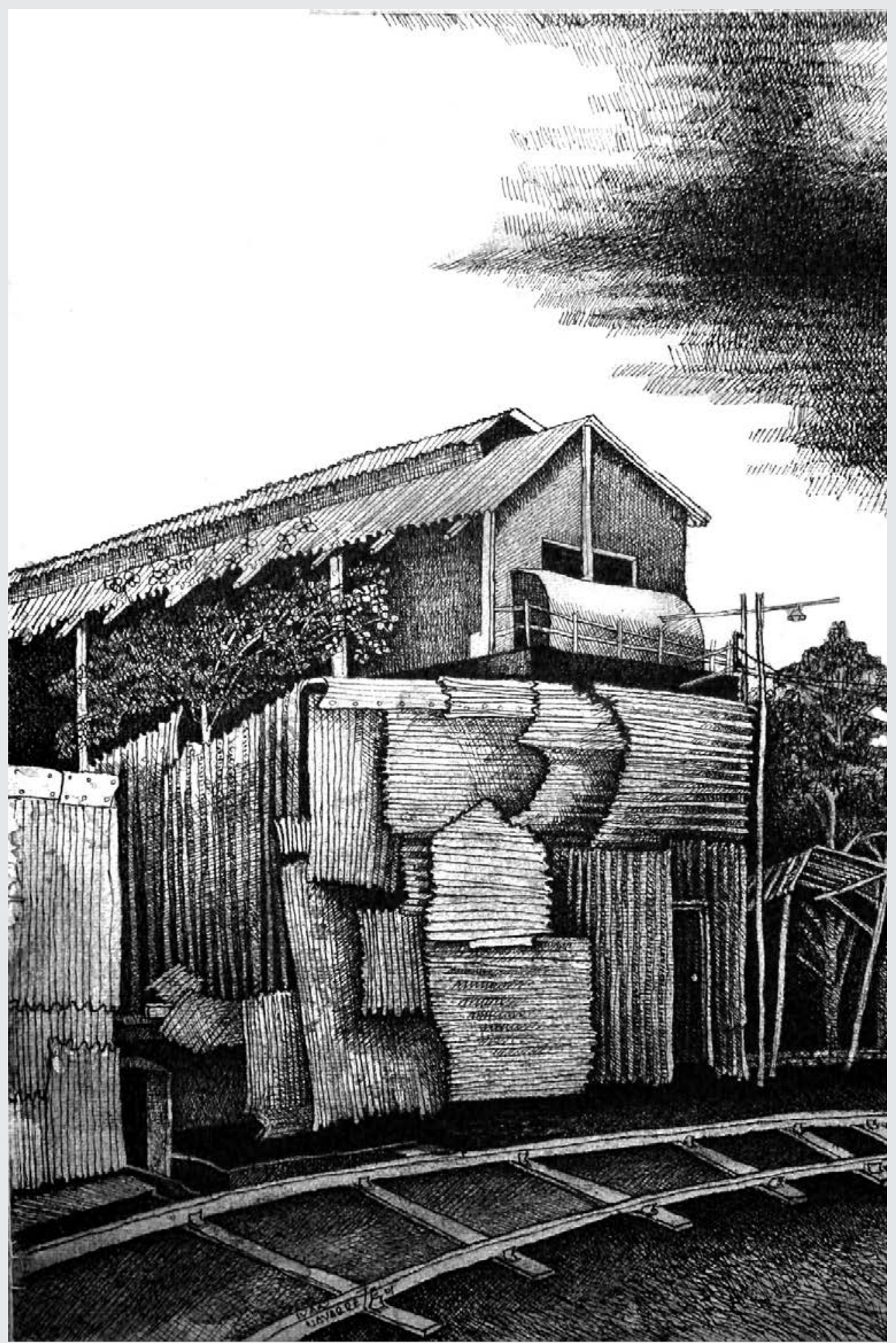

